\title{
KARAKTERISTIK ABSORBSI DAN IMPEDANSI MATERIAL AKUSTIK SERAT ALAM AMPAS TAHU (GLYCINE MAX) MENGGUNAKAN METODE TABUNG
}

\author{
Arlindo Rizal 1), Elvaswer ${ }^{2)}$, Yulia Fitri 1) \\ 1). Jurusan Fisika, FMIPA dan Kesehatan, Universitas Muhammadiyah Riau, \\ Sukajadi, Pekanbaru. \\ 2). Jurusan Fisika, FMIPA, Universitas Andalas, Kampus Unand, Limau Manis, \\ Padang, 25163. \\ Email :minangkabaumilanisti@yahoo.co.id,elvaswer@fmipa.unand.ac.id, \\ yuliafitri@umri.ac.id.
}

\begin{abstract}
ABSTRAK
Telah dilakukan pengujian karakteristk akustik dari material ampas tahu. Material tersebut merupakan material alternatif penyerap bunyi. Pengujian dilakukan dengan menggunakan metode tabung. Hasil pengujian menunjukkan bahwa material serat alam yang dicampur dengan lem memilki nilai koefisien absorbsi bunyi yang baik pada rentang frekuensi 1000-8000 Hz. Nilai koefisien absorbsi bunyi yang tinggi dimilki oleh material dengan pori-pori yang lebih besar $(0,90$ - 0,99). Selain koefisien absorbsi juga dilakukan pengujian nilai impedansi akustik. Hasilnya Menunjukkan bahwa perbandingan massa lem dengan ampas tahu diperoleh nilai impedansi yang baik $(7,75$ dan 8,33).
\end{abstract}

Kata kunci : serat alam, akustik, koefisien absorbsi bunyi, impedansi akustik, tabung akustik.

\section{PENDAHULUAN}

Sumber kebisingan akibat bunyi dihasilkan dari kendaraan dan industri. Kebisingan dapat dikendalikan dengan berbagai cara, salah satunya dengan mengasorbsi kebisingan tersebut dengan berbagai material akustik, misalnya pemilihan material bangunan, perencanaan, penempatan dan orientasi ruang. Jenis bahan peredam suara dapat diklasifikasikan menjadi bahan berpori, resonator dan panel. Pada umumnya bahan berpori akan menyerap energi suara atau bunyi yang lebih besar dibandingkan dengan jenis bahan lainnya, karena dengan adanya pori-pori maka gelombang suara dapat masuk ke dalam material tersebut. Material berongga memiliki frekuensi resonansi tertentu, sehingga bila gelombang bunyi yang datang sama dengan frekuensi tersebut maka kemampuan absorbsi bunyinya akan maksimum pada frekuensi tersebut. Pada bahan panel kemampuan material ini dalam menyerap bunyi bergantung pada kerapatan dari membran dan jarak membran dari dinding dan lebih efektik pada gelombang bunyi dengan frekuensi rendah. Bahan berpori yang biasa digunakan antara lain seperti papan serat (fiber board), plesteran lembut (soft plasters), mineral wools, selimut isolasi dan karpet (Doelle, 1993).

Komposit merupakan suatu struktur material yang dapat menggunakan serat sebagai material dasarnya. Serat alami digunakan sebagai material penguat (reinforcement), yang berfungsi menambah kekuatan dan kekakuan dalam menerima beban yang diinginkan. Serat yang terdapat di alam memiliki sifat-sifat yang cocok sebagai material dasar penguat pada komposit. Serat alam memiliki arah-arah serat yang acak dan sulit diatur. Serat alam pada umumnya memiliki kemampuan untuk menyerap bunyi yang cukup baik (Wirajaya, 2007).

Pemilihan ampas tahu sebagai material uji karena struktur serbuk pada ampas tahu yang halus dapat dijadikan sebagai material akustik karena banyak mengandung pori-pori 
material sehingga dapat mengabsorbsi bunyi (Santoso, 1993). Metode yang digunakan adalah metode tabung karena sederhana, praktis, dan materialnya mudah didapat. Tabung akustik yang digunakan mengacu pada penelitian terdahulu yang dilakukan oleh Rafika Andari (2008) dan Rudi Pratama Putra (2012).

Beberapa peneliti telah melakukan pengujian terhadap bahan serat alam, diantaranya adalah Koizumi telah mengembangkan bahan peredam suara dari serat bambu yang mutunya bisa sebagus glasswool. Begitu juga halnya dengan penggunaan jerami untuk dinding dan plafon yang bisa meningkatkan nilai koefisien absorbsi akustik hingga 0,9 .

Karakterisasi yang dilakukan untuk mengetahui bagaimana pengaruh frekuensi terhadap nilai koefisien absorbsi dan impedansi akustik dari material ampas tahu.

\section{METODE}

\subsection{Pembuatan Material Komposit}

Pada pembuatan material komposit, terlebih dahulu ampas tahu dikeringkan dengan menggunakan oven pada suhu $70^{\circ} \mathrm{C}$ selama 6 jam, sampai kadar air dalam ampas tahu mengering karena jika masih mengandung air, ampas tahu akan membusuk dan mudah hancur walaupun dicampur dengan matriks lem PVAc, hal seperti ini juga mempengaruhi struktur dari material komposit. Untuk menentukan jumlah matrik dan serat digunakan perbandingan massa antara serat dengan matrik yang digunakan (Santoso, 1993). Setelah ampas tahu mengering massa antara lem PVAc dengan ampas tahu ditimbang. Kemudian campurkan ampas tahu dengan lem sedikit demi sedikit dan diaduk sampai merata antara ampas tahu dengan lem. Setelah merata, masukkan ke dalam cetakan dan tekan sampai padat. Sebelumnya cetakan sudah diolesi dengan lilin agar setelah selesai mudah dilepas dari cetakan. Hasilnya didiamkan dalam cetakan sampai kering. Setelah itu, baru dilepaskan dari cetakan dengan memastikan lem telah kering dan merekat dengan baik.

Tabel 2.1 Perbandingan massa antara ampas tahu dengan matriks lem PVAc

\begin{tabular}{|c|c|c|}
\hline No & Ampas Tahu (gr) & Lem PVAc (gr) \\
\hline 1 & $30 \mathrm{gr}$ & $20 \mathrm{gr}$ \\
\hline 2 & $30 \mathrm{gr}$ & $25 \mathrm{gr}$ \\
\hline 3 & $30 \mathrm{gr}$ & $30 \mathrm{gr}$ \\
\hline 4 & $30 \mathrm{gr}$ & $35 \mathrm{gr}$ \\
\hline 5 & $30 \mathrm{gr}$ & $40 \mathrm{gr}$ \\
\hline
\end{tabular}

Digunakan tabung akustik untuk mengetahui kemampuan Ampas Tahu dalam menyerap bunyi. Tabung akustik yang digunakan adalah tabung akustik yang terbuat dari pipa paralon yang di set sedemikian rupa seperti yang ditunjukan pada Gambar 2.1. Dalam pengoperasiannya tabung akustik ini dihubungkan dengan beberapa alat lainnya yaitu amplifier, osiloskop, generator sinyal, adaptor, loudspeaker dan mikrofon. Tabung akustik ini di dalamnya terdapat sebuah mikrofon yang dapat digerakkan. Pada ujung tabung terdapat loudspeaker sebagai sumber gelombang sinusoidal dan material uji terdapat pada ujung tabung lainnya.

Mikrofon yang terdapat di dalam tabung dihubungkan dengan amplifier. Kemudian amplifier dihubungkan dengan osiloskop. Loudspeaker digunakan sebagai sumber bunyi yang dihubungkan dengan generator sinyal yang frekuensinya dapat divariasikan. Frekuensi yang digunakan dalam penelitian ini sesuai dengan frekuensi respon dari mikrofon yang digunakan yaitu frekuensi pada rentang octave band ; 500, 1000, 2000, 4000 dan $8000 \mathrm{~Hz}$. 


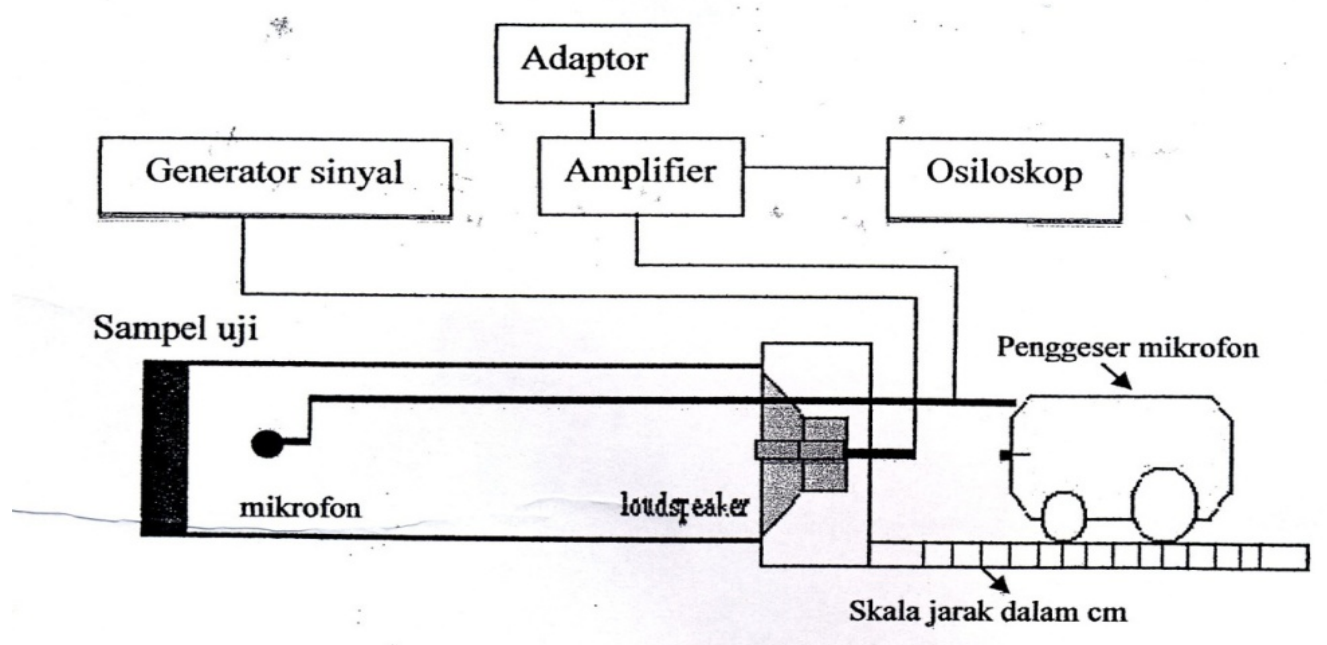

Gambar 2.1 Rangkaian tabung akustik

\section{HASIL DAN DISKUSI}

\subsection{Koefisien Absorbsi}

Dari Gambar 3.1 dapat dijelaskan untuk kelima sampel uji nilai koefisien absorbsi terendah berada pada frekuensi $500 \mathrm{~Hz}$ yaitu berkisar antara 0,62 sampai 0,72 . Nilai koefisien absorbsi terbesar berada pada frekuensi $8000 \mathrm{~Hz}$ dengan kisaran 0,87 sampai 0,99 . Pada kelima sampel uji semakin tinggi frekuensi semakin besar nilai dari koefisien absorbsi karena perbedaan panjang gelombang dari frekuensi tersebut. Frekuensi rendah dengan panjang gelombang yang panjang saat melewati material absorbsi berpori bunyi yang datang lebih banyak dipantulkan atau diteruskan daripada diserap. Frekuensi besar dengan panjang gelombang yang pendek saat melewati material absorbsi berpori bunyi yang datang lebih banyak diserap daripada dipantulkan atau diteruskan. Oleh karena itu pada material aborbsi berpori nilai koefisien absorbsinya lebih efektif pada frekuensi tinggi.

Dari data di atas dapat dijelaskan bahwa komposisi lem yang sedikit akan menyerap bunyi lebih baik daripada lem dengan komposisi banyak karena gelombang bunyi yang datang akan diserap oleh material yang banyak mengandung pori-pori atau material dengan porositas yang tinggi sehingga gelombang bunyi lebih banyak diserap daripada dipantulkan. Sedangkan material dengan komposisi lem yang banyak daya serapnya relatif kurang karena lem menutupi hampir seluruh pori-pori dari material absorbsi sehingga porositas dari bahan menjadi rendah sehingga gelombang bunyi lebih banyak dipantulkan. 


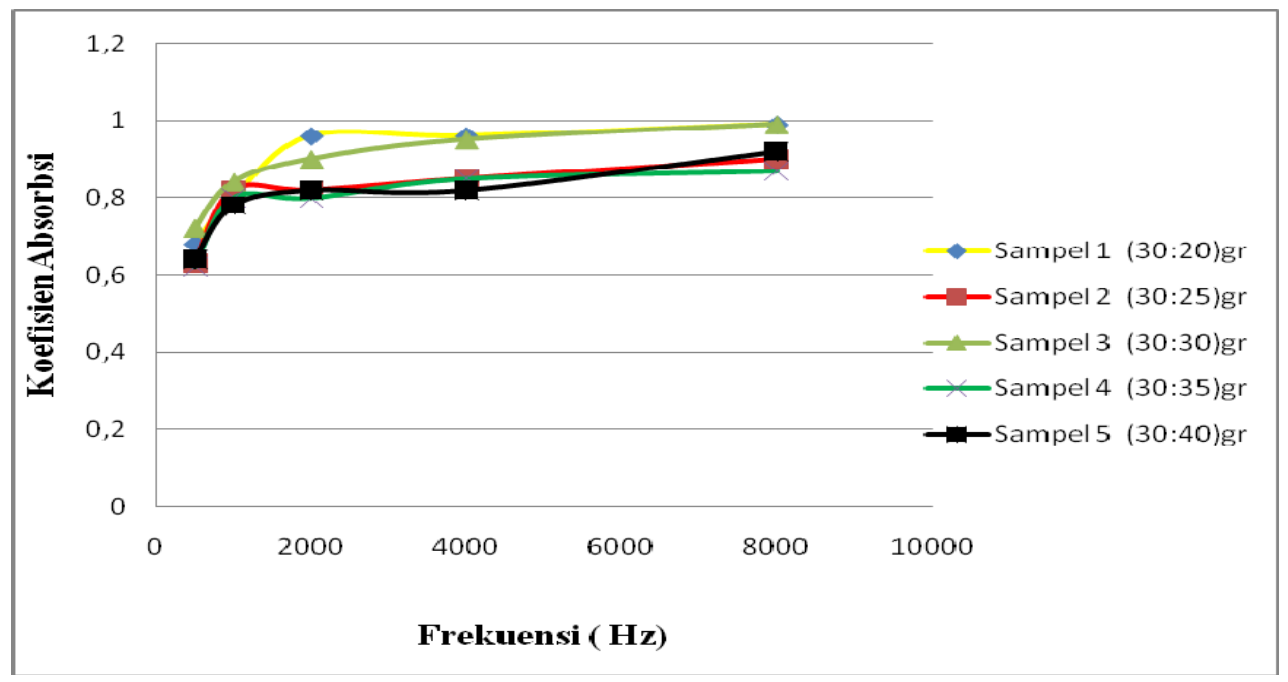

Gambar 3.1 Grafik hubungan koefisien serapan bunyi material dengan variasi massa

\subsection{Impedansi Akustik}

lem.

Dari Gambar 3.2 dapat dijelaskan untuk kelima sampel uji nilai dari impedansi akustik terendah berada pada frekuensi $500 \mathrm{~Hz}$ dengan kiasran 1,24-1,48. Nilai impedansi akustik tertinggi berada pada frekuensi $2000 \mathrm{~Hz}$ dan $8000 \mathrm{~Hz}$ pada sampel 1 dan 3 dengan nilai pada sampel 1 ( 6,90 dan 8,33) dan sampel 3 ( 4,00 dan 7,75)

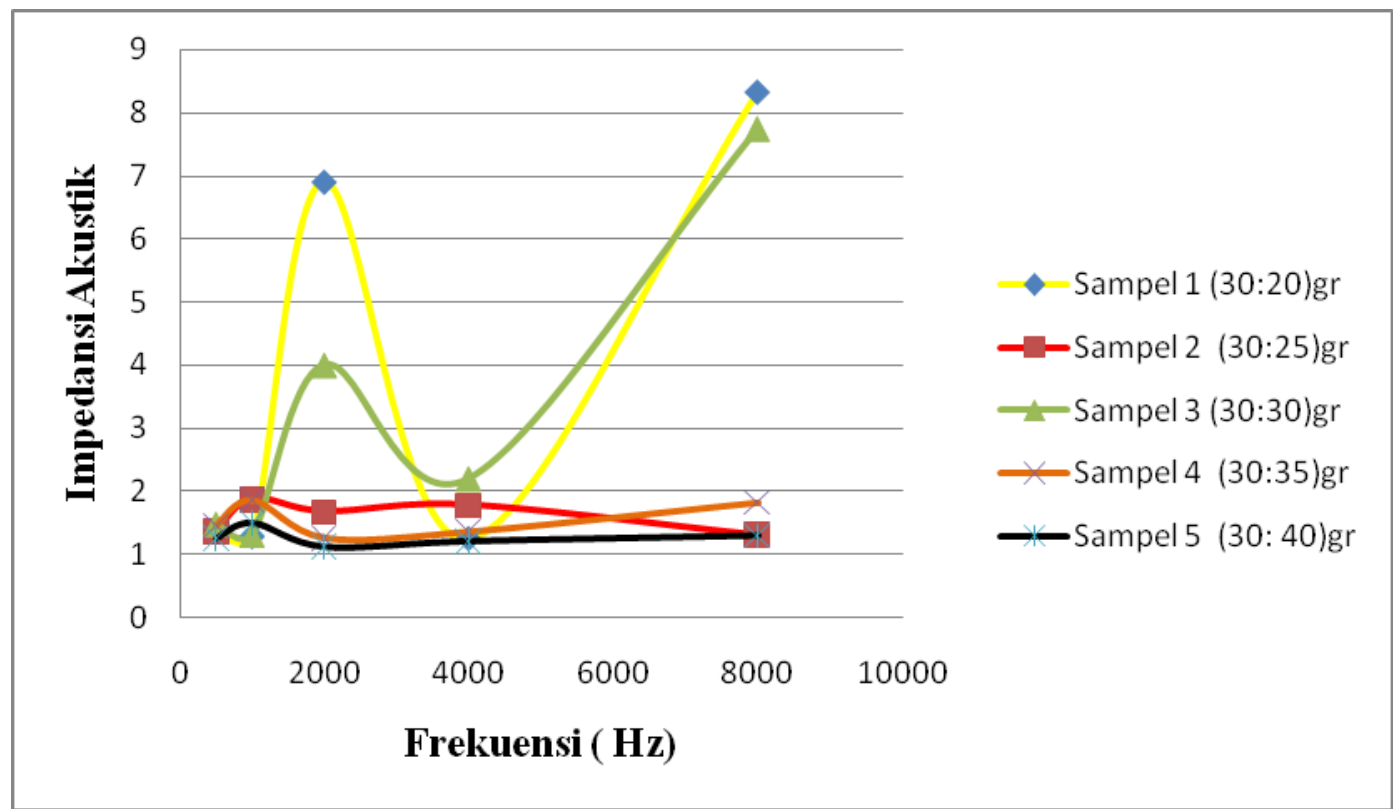

Gambar 3.2 Grafik hubungan impedansi akustik material dengan variasi

massa lem

Dari data di atas dapat dijelaskan bahwa komposisi lem yang sedikit akan memberikan impedansi akustik lebih baik daripada komposisi lem yang banyak karena gelombang bunyi yang datang akan diserap oleh material yang banyak mengandung pori-pori atau material dengan porositas yang tinggi. Sedangkan material dengan komposisi lem yang banyak impedansinya relatif kurang karena lem menutupi hampir seluruh pori-pori dari material absorbsi sehingga porositas dari bahan menjadi rendah. 


\section{KESIMPULAN}

Nilai koefisien absorbsi terbesar adalah 0,99 yang terdapat pada frekuensi $8000 \mathrm{~Hz}$ dan didapatkan pada bahan dengan massa 30 gr : 20 gr dan 30 gr : 30 gr. Nilai impedansi akustik terbesar adalah 8,33 yang terdapat pada frekuensi $8000 \mathrm{~Hz}$ dan didapatkan pada bahan dengan massa 30 gr : 20 gr.

\section{DAFTAR PUSTAKA}

1. Doelle, L, L, Prasetyo, L, 1993, Akustik Lingkungan, Erlangga. Jakarta.

2. Koizumi, T, N, 2002, The Development Of Sound Absorbing Material Using Natural Bambu Fiber, Jurnal Universitas Doshiba, WIT Press: Jepang.

3. Mediastika, C, E, 2009, Material Akustik Pengendali Kualitas Bunyi Pada Bangunan, ANDI. Jogjakarta.

4. Wirajaya, A, 2007, Karakteristik Komposit Sandwich Serat Alami Sebagai Absorber Bunyi, Tugas Akhir S1 ITB, Bandung.

5. Santoso, 1993, Karakterisasi Ampas Tahu dan Pemanfaatannya Sebagai Material Komposit, UNIMED.

6. Russell, D, A, Absorption Coefficients and Impedance, Scienc and Mathematic Department, GMI Engineering \& Management Institute Flint, MI, 48504.

7. Andari, Rafika, 2008, Pengujian Karakteristik Absorbsi Dan Impedansi Material Akustik Serat Alam Menggunakan Metode Tabung. Jurusan Fisika, FMIPA, Universitas Andalas.

8. Pratama Putra, Rudi, 2012, Pengujian Karakteristik Absorbsi dan Impedansi Akustik Serat Alam Serabut Buah Sawit (Elaeis Guineensis) Menggunakan Metode Tabung. Jurusan Fisika, FMIPA,Universitas Andalas. 